\title{
Estandarización de una reacción en cadena de la polimerasa en tiempo real (qPCR) para la detección de Strongyloides stercoralis en muestras de materia fecal
}

\author{
Standardization of a real-time polymerase chain reaction (qPCR) \\ for the detection of Strongyloides stercoralis in stool samples
}

\section{Laura F. Campo-Polanco MSc ${ }^{1}$, José M. Hernández-Sarmiento PhD², Luz E. Botero-Palacio PhD ${ }^{3}$, Lina A. Gutiérrez-Builes $P h D^{4}$}

Introducción: el diagnóstico de estrongiloidiasis se realiza de rutina en los laboratorios clínicos; sin embargo, su detección se dificulta debido a la baja excreción parasitaria y la baja sensibilidad de las pruebas parasitológicas empleadas. Objetivo: diseñar y estandarizar una $P C R$ en tiempo real ( $q P C R$ ) para la detección de $A D N$ de Strongyloides stercoralis en muestras de materia fecal. Materiales $\boldsymbol{y}$ métodos: se establecieron las condiciones de qPCR y se evaluaron: a) la especificidad analítica mediante análisis BLASTn de secuencias obtenidas de muestras positivas para Strongyloides stercoralis, b) sensibilidad analítica mediante diluciones seriadas de muestras que contenían larvas de Strongyloides stercoralis y c) la ocurrencia de reacciones cruzadas con otros parásitos e inhibidores de la

\footnotetext{
${ }^{1}$ Microbióloga y Bioanalista, MSc en Microbiología y Bioanálisis. Docente de cátedra, Universidad de Antioquia. Investigadora, Grupo de Biología de Sistemas, Escuela de Ciencias de la Salud, Facultad de Medicina, Universidad Pontificia Bolivariana. Medellín, Colombia. Correspondencia: Calle 78B \#72A-109, Bloque B (cuarto piso). Teléfono: 5744488388 ext. 19-333. Correo electrónico: laura.campolanco@gmail.com ${ }_{2}^{2}$ Médico, MSc y PhD en Ciencias Médicas. Docente, Universidad Pontificia Bolivariana. Investigador, Unidad de Bacteriología y Micobacterias, Corporación para Investigaciones Biológicas (CIB). Medellín, Colombia.

${ }^{3}$ Bacterióloga y Laboratorista Clínica, Especialista en Gerencia en Economía y Finanzas de la Salud, MSc en Ciencias Básicas Biomédicas, PhD en Ciencias Médicas. Docente e investigadora, Grupo de Biología de Sistemas, Escuela de Ciencias de la Salud, Facultad de Medicina, Universidad Pontificia Bolivariana. Medellín, Colombia.

${ }^{4}$ Bacterióloga y Laboratorista Clínica, PhD en Ciencias Básicas Biomédicas. Docente e investigadora, Grupo de Biología de Sistemas, Escuela de Ciencias de la Salud, Facultad de Medicina, Universidad Pontificia Bolivariana. Medellín, Colombia.
}

Conflicto de intereses: los autores declaran que no tienen conflicto de intereses Medicina \& Laboratorio 2016; 22: 459-478

Módulo 19 (Investigación), número 49. Editora Médica Colombiana S.A. $2016^{\circ}$

Recibido el 18 de septiembre de 2016; aceptado el 07 de octubre de 2016 
amplificación. Resultados: se amplificó un fragmento de 101 pb del gen $18 \mathrm{~S}$ del ARN ribosomal. El valor de Ct osciló entre 23 y 29, tomando un Ct $\leq 35$ como el punto de corte para muestras positivas. El análisis BLASTn de las secuencias obtenidas mostró un porcentaje de identidad del $98 \%$ con secuencias $18 \mathrm{~S}$ del ARN ribosomal de Strongyloides stercoralis reportadas en la NCBI. El límite inferior de detección de la $q P C R$ fue $0,9 \mathrm{ng} / \mu \mathrm{L}$. No se evidenció reacción cruzada con Ascaris lumbricoides, Trichuris trichiura, Uncinarias, Hymenolepis nana, Entamoeba histolytica/Entamoeba dispar, Entamoeba hartmanni, Giardia intestinalis e Iodamoeba bütschlii. No se detectaron inhibidores en las muestras de materia fecal. Conclusiones: la sensibilidad y la especificidad analítica de la qPCR comparado con el examen directo de heces son del 100\%; sin embargo, aún no es posible interpretar su utilidad clínica.

Palabras clave: Strongyloides stercoralis, estandarización, reacción en cadena de la polimerasa, $q P C R$, técnicas de diagnóstico molecular.

Introduction: the diagnosis of strongyloidiasis is performing routinely in clinical laboratories; however, its detection is difficult due to low parasitic excretion and low sensitivity of the parasitological tests employed. Objective: to design and standardize a real-time PCR ( $q P C R$ ) for the detection of Strongyloides stercoralis DNA in stool samples. Materials and methods: qPCR conditions were established and it were assessed: a) analytical specificity by BLASTn analysis of sequences obtained from samples positive for Strongyloides stercoralis, $b$ ) analytical sensitivity by serial dilutions of samples containing Strongyloides stercoralis larvae and c) the occurrence of cross-reactions with other parasites and amplification inhibitors. Results: a $101 \mathrm{bp}$ fragment of the 185 ribosomal RNA gene was amplified. The value of Ct ranged from 23 and 29, with a Ct value $\leq 35$ as a cut-off point for positive samples. BLASTn analysis of the obtained sequences showed an identity percentage of $98 \%$ with $18 \mathrm{~S}$ ribosomal RNA sequences of Strongyloides stercoralis reported in the NCBI. The qPCR lower limit of detection was $0.9 \mathrm{ng} / \mu \mathrm{L}$. There was no cross-reaction with Ascaris lumbricoides, Trichuris trichiura, Uncinarias, Hymenolepis nana, Entamoeba histolytica/Entamoeba dispar, Entamoeba hartmanni, Giardia intestinalis, and Iodamoeba bütschlii. No inhibitors were detected in the stool samples. Conclusion: the sensitivity and analytical specificity of qPCR compared to direct examination of feces are $100 \%$; however, it is still not possible to interpret their clinical utility.

Key words: Strongyloides stercoralis, standardization, polymerase chain reaction, qPCR, molecular diagnostic techniques.

Campo-Polanco LF, Hernández-Sarmiento JM, Botero-Palacio LE, Gutiérrez-Builes LA. Estandarización de una reacción en cadena de la polimerasa en tiempo real ( $q P C R$ ) para la detección de Strongyloides stercoralis en muestras de materia fecal. Medicina \& Laboratorio 2016; 22: 459-478. 
T a estrongiloidiasis es una infección parasitaria causada por el nematodo intestinal Strongyloides stercoralis [1]. Esta infección presenta, generalmente, un curso asintomático, pero se puede complicar en algunos casos específicos, principalmente de inmunosupresión [2-4]. Esta parasitosis se presenta con mayor frecuencia en los países tropicales y subtropicales donde las condiciones higiénico-sanitarias son deficientes [5]. En 2013 se estimó que existían alrededor de 370.000.000 de personas infectadas por Strongyloides stercoralis en todo el mundo [6][7], se reportó una prevalencia que variaba entre el $10 \%$ y el $70 \%$ en Latinoamérica.

Strongyloides stercoralis presenta complejidad en su ciclo biológico, el cual alterna entre estadios de vida libre y de vida parasitaria [8]; además, posee potencial para generar autoinfección debido a su capacidad de reproducirse y madurar hasta el estadio infectivo al interior del hospedero. Este proceso puede llevar a infecciones persistentes que resultan en enfermedad crónica, que al ser de sintomatología inespecífica dificulta el diagnóstico de la infección [9].

El diagnóstico tradicional de la estrongiloidiasis se realiza mediante la detección microscópica de las larvas rabditiformes en las heces por examen coproparasitológico. No obstante, el hallazgo de las formas parasitarias a menudo se dificulta debido a dos aspectos principales: a) la ausencia de síntomas y las bajas cargas parasitarias en la mayoría de los casos de estrongiloidiasis y b) el bajo desempeño diagnóstico de los métodos coproparasitológicos utilizados de manera tradicional en los laboratorios clínicos [10].

El examen directo de heces (método de Beaver) y el método de formol éter o Ritchie modificado son los más utilizados para la detección de Strongyloides stercoralis; el primero es una técnica sencilla y de bajo costo, pero presenta una sensibilidad del $30 \%$, por lo que requiere el procesamiento de hasta siete muestras seriadas para aumentar la sensibilidad al 70\% y, a menudo, complementar el diagnóstico empleando técnicas de concentración como la de formol éter o Ritchie modificado y la técnica de formalina etil-acetato [11]. No obstante, una evaluación diagnóstica de estas dos pruebas mediante metanálisis demostró su poca capacidad para predecir la presencia o ausencia de la infección, debido a que presentan un bajo desempeño, eficiencia y seguridad diagnóstica en la detección de Strongyloides stercoralis [12], principalmente cuando la infección se encuentra en fase crónica $[13,14]$.

Otras pruebas que permiten el diagnóstico de la estrongiloidiasis, y que han superado al examen directo de heces en la detección de larvas, son el cultivo en placa de agar, cuya sensibilidad varía entre el $80 \%$ y el $95 \%$, y el método Baermann, que varía entre el $60 \%$ y el $85 \%[15,16]$. Pese a brindar mejores resultados en el diagnóstico, el hecho de que estos métodos sean laboriosos y requieran mayor 
cantidad de muestra y de tiempo de procesamiento dificulta su uso de manera rutinaria en los laboratorios clínicos [17].

Los avances en el diagnóstico de Strongyloides stercoralis en muestras de heces ha incluido la realización de pruebas serológicas tipo ELISA $[18,19]$, inmunofluorescencia indirecta $[20,21]$, aglutinación en partículas de gelatina $[22,23]$ y la reacción en cadena de la polimerasa en tiempo real (qPCR) [24-26]. Algunos de estos métodos se han desarrollado y evaluado sin éxito y otros, como el ELISA, presentan deficiencias en la sensibilidad y la especificidad, ya que su resultado está condicionado al tipo de inmunoglobulina que detecta, la población estudiada y el método empleado $[27,28]$. Otros aspectos importantes en estos ensayos es que pueden presentar reacciones cruzadas con otros helmintos y no permiten diferenciar entre las infecciones actuales y pasadas; además, en ocasiones pueden darse reacciones cruzadas con las parasitosis producidas por otros nematodos [5].

Varios enfoques moleculares han sido desarrollados para la detección de ADN de patógenos entéricos [29-32]. En el caso específico de Strongyloides stercoralis se ha amplificado mediante reacción en cadena de la polimerasa (PCR), en la mayoría de las pruebas, el marcador molecular $18 \mathrm{~S}$ del ARN ribosomal [24,33-36] y, en otras pocas, las regiones del espaciador transcrito interno 1 y 2 (ITS1 e ITS2) [37,38]. En algunos países de Latinoamérica se ha evaluado la PCR para el diagnóstico de Strongyloides stercoralis [39], sin embargo, en Colombia aún no se encuentran disponibles estas técnicas como método diagnóstico de la estrongiloidiasis.

Dada la diversidad genética observada en los diferentes aislamientos de Strongyloides stercoralis, no solo entre aislamientos larvarios de diferentes regiones geográficas, sino también de aislamientos obtenidos de algunas especies de hospederos susceptibles a la infección por este nematodo ( $p$. ej. humanos, chimpancés y perros), en los cuales puede desarrollar su ciclo biológico completo [40-42], y teniendo en cuenta que se ha documentado la transmisión zoonótica de Strongyloides stercoralis, es importante evaluar el comportamiento de la prueba molecular por PCR como método diagnóstico de estrongiloidiasis. Con base en lo anterior, el objetivo del presente estudio fue evaluar la validez interna de una PCR en tiempo real para la detección de Strongyloides stercoralis en muestras de materia fecal.

\section{Materiales y métodos}

\section{Tipo de estudio y consideraciones éticas}

La presente investigación corresponde a la fase de estandarización de un estudio de validación de prueba diagnóstica. Los procedimientos realizados no presentaron ningún riesgo, ya que durante su ejecución se cumplieron los principios éticos fundamentales que regulan la conducta ética, regidos por El Código de Núremberg (1947), la Declaración de Helsinki (promulgada en 1964 y enmen- 
dada en Corea en 2008), y la norma nacional 008430 para la investigación en salud. Además, contó con la aprobación del Comité de Investigación en Salud de la Universidad Pontificia Bolivariana.

\section{Descripción de muestras de materia fecal para la estandarización de la reacción en cadena de la polimerasa en tiempo real (qPCR)}

Durante el proceso de estandarización de la reacción en cadena de la polimerasa en tiempo real (qPCR) evaluada en este trabajo se analizaron 20 muestras de heces humanas. Cuatro de las muestras procedían de una institución hospitalaria de la ciudad de Medellín (Colombia), donde fueron usadas para diagnóstico clínico y en las que se había determinado la presencia de larvas rabditiformes de Strongyloides stercoralis mediante examen directo de heces y concentración de Ritchie modificada, sin presencia de otros parásitos intestinales patógenos o comensales. La fracción restante de estas muestras biológicas fue anonimizada (razón por la que no se requirió de consentimiento informado por parte de los individuos de los que procedían) y fue usada en el presente trabajo con propósitos exclusivos de investigación.

Las cuatro muestras se emplearon como controles positivos durante todo el proceso de estandarización de la técnica y fueron codificadas como SF1, SF2, SF3 y SF4. SF1 correspondía a un paciente con un síndrome de hiperinfección, determinado por la observación de varios estadios del parásito al examen directo, mientras que los controles SF2, SF3 y SF4 pertenecían a pacientes con cargas parasitarias altas (sin hiperinfección), establecidas por la visualización de dos a cinco larvas rabditiformes por campo. A estas muestras no se les adicionó ningún tipo de preservante y fueron almacenadas a $-20^{\circ} \mathrm{C}$ hasta la extracción del ADN genómico.

Las 16 muestras restantes provenían de individuos habitantes de zonas rurales del departamento del Chocó, Colombia, las cuales mediante examen directo de heces y concentración de Ritchie modificada arrojaron resultados negativos para Strongyloides stercoralis y fueron positivas para otros parásitos intestinales tanto comensales como patógenos. La selección de estos individuos se realizó mediante un muestreo por conveniencia y se estableció como mínimo un total de 15 participantes, mayores de edad, de ambos géneros, que decidieron hacer parte del estudio de manera voluntaria y firmaron el consentimiento informado.

\section{Elección del protocolo de extracción del ADN genómico a partir de muestras de materia fecal}

Aunque diferentes casas comerciales ofrecen estuches específicos para la extracción de ADN genómico a partir de muestras de materia fecal de humanos, en la fase inicial de este estudio se realizó una revisión de artículos originales cuyo objetivo había sido la estandarización de protocolos para la detección de parásitos intestinales en muestras de materia fecal usando pruebas moleculares, 
en la que se encontró que en su mayoría se usaban protocolos de extracción diferentes a los ofrecidos de manera específica para este propósito por las casas comerciales [24].

Con base en lo anterior, para la selección de un buen método de extracción de ADN genómico, que permitiera la ejecución del presente trabajo, se compararon dos estuches comerciales referenciados ampliamente $[25,26,33,43]$ para su uso, con propósitos similares al del presente estudio: QIAamp DNA Stool Mini Kit (QIAGEN ${ }^{\circledR}$, Hilden, Alemania) y QIAamp DNA Mini Kit (QIAGEN ${ }^{\circledR}$, Hilden, Alemania).

De manera independiente se realizó la extracción de ADN genómico de las cuatro muestras de materia fecal positivas (SF1 a SF4) para Strongyloides stercoralis para comparar y seleccionar el método más eficiente en términos de calidad y cantidad de ADN extraído a partir de este tipo de muestras. Para ambos métodos se realizó la extracción a partir de 100 mg de materia fecal.

El método comercial QIAamp DNA Stool se aplicó siguiendo las recomendaciones de la casa fabricante y para el QIAamp DNA Mini Kit se emplearon las modificaciones reportadas por Basuni y colaboradores (2011) [24], en las que se sugiere la adición de $200 \mu \mathrm{L}$ de PBS (del inglés, Phosphate buffered saline; $\mathrm{pH} 7,2$ ) al $2 \%$ de polivinilpolipirrolidona (PVPP; Sigma, Steinheim, Alemania) y la incubación de la muestra a $100{ }^{\circ} \mathrm{C}$ durante 10 minutos, seguido de la adición a la mezcla de $200 \mu \mathrm{L}$ del tampón de lisis (ATL) suministrado en el estuche de extracción y 40 $\mu \mathrm{L}$ de proteinasa $\mathrm{K}$ y de la incubación a $56{ }^{\circ} \mathrm{C}$ durante toda la noche; posteriormente, se aplicó el protocolo como lo especifica el fabricante.

Cada muestra (control positivo) fue extraída por triplicado empleando las mismas condiciones en cada protocolo utilizado. Para verificar la concentración de ADN (ng/ $\mu \mathrm{L})$ y el índice de pureza (A260/A280) en cada uno de los ensayos el ADN obtenido fue analizado en el equipo NanoDrop 2000 $c^{\circledR}$ (Thermo Fisher Scientific, Massachusetts, Estados Unidos). A partir de dichos datos se calcularon los promedios y las desviaciones estándar para la concentración de ADN obtenida y el índice de pureza de cada método de extracción por separado, y se realizó el análisis estadístico empleando el software SPSS para Windows versión 21 (IBM Corporation, Nueva York, Estados Unidos).

Además de lo anterior, se realizó dilución seriada en base 10 a una de las muestras extraídas con cada protocolo para determinar la presencia de inhibidores de la PCR mediante la comparación de los valores del ciclo umbral o Ct (del inglés, threshold cycle), correspondiente al número de ciclo de la PCR en que se detecta el producto amplificado, obtenidos tanto para la detección molecular del parásito como para el control positivo interno usado en el protocolo de PCR en tiempo real (véase descripción a continuación). 


\section{Análisis de la especificidad analítica in silico y mediante PCR} convencional de los cebadores elegidos para la amplificación del gen $18 \mathrm{~S}$ del ARN ribosomal

Para la amplificación específica del gen $18 \mathrm{~S}$ del ARN ribosomal de Strongyloides stercoralis se empleó un par de cebadores reportados por Verweij y colaboradores (2009) [34]. Para la selección inicial de estos cebadores se consideró el hecho de que habían sido aplicados en distintas zonas geográficas, e incluso se han incorporado en un método pentaplex de PCR en tiempo real para la detección de geohelmintos, lo que de alguna manera sugería una especificidad de los cebadores y la ausencia de reacciones cruzadas con otros parásitos que son también de alta importancia en nuestro medio, como las uncinarias (Ancylostoma duodenale/Necator americanus) y Ascaris lumbricoides [24].

De manera adicional, la especificidad de los cebadores se verificó mediante varias herramientas bioinformáticas y con procedimientos de laboratorio, tal como se explica a continuación. Inicialmente, se llevó a cabo un análisis de identidad de las secuencias de los cebadores usando el programa Nucleotide-BLAST ${ }^{\circledR}$ (del inglés, Basic Local Alignment Search Tool, NCBI, National Library of Medicine, Maryland, Estados Unidos); posteriormente, se efectuó el análisis de la calidad del diseño de dichos cebadores usando el software Oligoanalyser 3.1 (Integrated DNA Technologies, Inc., Iowa, Estados Unidos), seguido de una simulación de amplificación mediante una PCR electrónica en el software FastPCR 6.5 (PrimerDigital Ltd., Helsinki, Finlandia), equivalente a la PCR in silico.

Previo a la implementación del procedimiento de PCR en tiempo real se realizó una PCR convencional usando un termociclador T100 ${ }^{\mathrm{TM}}$ (Bio-Rad Laboratories, California, Estados Unidos), en la que se amplificaron los controles positivos descritos anteriormente para verificar el tamaño del amplicón y obtener un producto de PCR purificado para realizar la secuenciación bidireccional. Las condiciones de la PCR se emplearon como las describen Basuni y colaboradores (2011) [24], aplicando algunas modificaciones en los parámetros de concentración final de los cebadores (200 nM) y con una disminución del número de ciclos de 50 a 40 .

El producto de amplificación por PCR de los cuatro controles positivos fue enviado para secuenciación bidireccional en Macrogen USA (Maryland, Estados Unidos). Las secuencias obtenidas fueron editadas en el software Chromas Lite versión 2.1.1 (Technelysium Pty Ltd., Queensland, Australia) y alineadas en el programa BioEdit (Biological Sequence Alignment Editor) versión 7.1.9 (Ibis Bioscience, California, Estados Unidos); posteriormente, se determinó el porcentaje de identidad al comparar las secuencias de Strongyloides stercoralis obtenidas de los controles positivos frente a las secuencias reportadas en el NCBI mediante un análisis BLASTn. 


\section{Amplificación del gen $18 \mathrm{~S}$ de la subunidad pequeña de ARN ribosomal mediante qPCR}

En la qPCR se usaron los cebadores descritos previamente para la amplificación del gen $18 \mathrm{~S}$ del ARN ribosomal de Strongyloides stercoralis y una sonda TaqMan (Custom TaqMan ${ }^{\circledR}$, MGB Probes, Applied Biosystems ${ }^{\circledR}$, Thermo Fisher Scientific, Massachusetts, Estados Unidos) con una secuencia de 19 nucleótidos específica para Strongyloides stercoralis, marcada con FAMTM, previamente descrita por Basuni y colaboradores (2011) [24], empleando el estuche comercial de Applied Biosystems ${ }^{\circledR}$ $\operatorname{TaqMan}^{\circledR}$ Universal PCR Master Mix (Thermo Fisher Scientific, Massachusetts, Estados Unidos) siguiendo las recomendaciones del fabricante.

Para la optimización de los parámetros de la qPCR para el diagnóstico de Strongyloides stercoralis se realizaron modificaciones mediante el uso de gradientes de concentración para los cebadores y para la sonda. Con el fin de mejorar el rendimiento de la amplificación se adicionó albúmina de suero bovino (BSA; Thermo Scientific Bovine Serum Albumin, Thermo Fisher Scientific, Massachusetts, Estados Unidos) y dimetil sulfoxido (DMSO, Fluka-Sigma-Aldrich, Steinheim, Alemania) a concentraciones finales de $0,1 \mathrm{mg} / \mathrm{mL}$ y $1 \%$, respectivamente.

En todas la pruebas se introdujo un ADN exógeno o IPC (TaqMan ${ }^{\circledR}$ Exogenous Internal Positive control, Applied Biosystems ${ }^{\circledR}$, Thermo Fisher Scientific, Massachusetts, Estados Unidos) como control positivo interno de la reacción para evaluar la presencia de inhibidores en las muestras de materia fecal y como control negativo se utilizó agua ultrapura. El proceso de optimización de la qPCR para la detección de Strongyloides stercoralis se llevó a cabo en el termociclador ABI Applied Biosystem 7500 fast (Applied Biosystem ${ }^{\circledR}$, Thermo Fisher Scientific, Massachusetts, Estados Unidos).

\section{Evaluación de la sensibilidad analítica}

Para la estimación de la sensibilidad analítica a partir de una muestra de materia fecal positiva para Strongyloides stercoralis e identificada previamente mediante el método de Ritchie modificado se realizó el aislamiento de materia fecal en placa de agar para obtener estadios larvarios del parásito. Después de evaluar la positividad del agar, usando un estereomicroscopio, se realizó un lavado de la superficie de la placa de agar con PBS pH 7, se recolectó el material y se llevó a cabo el recuento de larvas en una cámara UniSYSTEMTM SLIDE-10 (Thermo Fisher Scientific, Massachusetts, Estados Unidos).

Posteriormente, se retiró la muestra de cada pozo que contenía una, dos y cuatro larvas y cada una fue depositada en un vial de 1,5 mL para la extracción del ADN. La trasferencia de las larvas a cada vial fue verificada mediante visualización microscópica. El producto de la extracción de ADN fue cuantificado en el NanoDrop $2000 c^{\circledR}$ (Thermo Scientific, Massachusetts, Estados Unidos) y a partir de la muestra con cuatro larvas de Strongyloides stercoralis, de la cual se obtuvo una 
concentración de ADN de $2,6 \mathrm{ng} / \mu \mathrm{L}$, se realizaron diluciones seriadas en base 10 . Finalmente, para cada concentración de ADN se realizaron cuatro repeticiones de qPCR para evaluar la reproducibilidad de los ensayos.

\section{Evaluación de la especificidad analítica}

En la determinación de la especificidad analítica de la qPCR diseñada para la detección de Strongyloides stercoralis se evaluó la existencia de reacciones cruzadas con otros parásitos intestinales mediante el procesamiento de un grupo de 20 muestras de materia fecal caracterizadas mediante detección microscópica, examen directo de heces y concentración de Ritchie modificada. Las muestras que solo contenían larvas de Strongyloides stercoralis se emplearon como controles positivos.

De manera adicional, se seleccionaron y se procesaron mediante qPCR muestras positivas para geohelmintos como: Ascaris lumbricoides, Trichuris trichiura, Ancylostoma duodenale/Necator americanus e Hymenolepis nana. Así mismo, se determinó la reactividad cruzada con otros parásitos como Entamoeba histolytica/ Entamoeba dispar, Entamoeba hartmanni, Entamoeba coli, Endolimax nana, Giardia intestinalis, Chilomastix mesnili e Iodamoeba bütschlii. También se emplearon muestras con poliparasitismo por Ascaris lumbricoides, Trichuris trichiura, Ancylostoma duodenale/Necator americanus e Hymenolepis nana y algunos otros protozoos patógenos y comensales. Se realizaron tres repeticiones de este ensayo.

Cuatro de los productos de PCR con un valor de Ct entre 35 y 40 obtenidos en este ensayo fueron tomados al azar para evaluar la presencia o ausencia de ADN (positividad o negatividad) de Strongyloides stercoralis en un gel de agarosa al 2\%, con Ez-visión ${ }^{\circledR}$ (AMRESCO LLC, Ohio, Estados Unidos) como revelador.

\section{Determinación de la reproducibilidad de la qPCR}

Para determinar la eficiencia de la reacción de qPCR y verificar la linealidad del método (para evaluar su potencial como método cuantitativo) se construyó una curva estándar a partir de una muestra de ADN genómico obtenido de una muestra de materia fecal sometida a diluciones seriadas en base 10 desde una concentración inicial de ADN de $24,8 \mathrm{ng} / \mu \mathrm{L}$ hasta $2,48 \times 10^{-15} \mathrm{ng} / \mu \mathrm{L}$. En la misma reacción de qPCR se realizaron tres réplicas por cada dilución y se determinaron el coeficiente de determinación $\left(R^{2}\right)$ y la eficiencia de la prueba con el software 7500 fast v2.0.5 (Applied Biosystem ${ }^{\circledR}$, Thermo Fisher Scientific, Massachusetts, Estados Unidos); además, se verificó dicho cálculo usando el programa SPSS versión 21.

Las mismas diluciones en base 10 descritas anteriormente se sometieron a tres reacciones de qPCR en un mismo día para determinar la reproducibilidad intraensayo, y en tres días diferentes para comprobar la reproducibilidad interensayo. Los productos amplificados mediante qPCR en cada uno de los ensayos fueron 
analizados en una electroforesis en gel de agarosa al 2\% usando GelRed (Thermo Fisher Scientific, Massachusetts, Estados Unidos) como reactivo intercalante para la visualización de las bandas de ADN y la verificación de la presencia del producto de PCR esperado.

\section{Resultados}

\section{Extracción de ADN genómico de Strongyloides stercoralis}

El estuche de extracción de ADN genómico que mostró mejores resultados en cuanto al índice de pureza del ADN obtenido luego del procedimiento fue el QIAamp DNA Mini Kit bajo las modificaciones del protocolo reportado por Basuni y colaboradores (2011) [24]. El promedio de la concentración de ADN (ng/ $\mu \mathrm{L}$ ) y la pureza (índice 260/280) para los cuatro controles positivos extraídos con el estuche QIAamp DNA Stool Mini Kit fue de $26,8 \mathrm{ng} / \mu \mathrm{L}, 55,3 \mathrm{ng} / \mu \mathrm{L}, 3,5 \mathrm{ng} / \mu \mathrm{L}$ y 2,3 $\mathrm{ng} / \mu \mathrm{L}$ y $1,33,2,2 ; 2,1$ y 2,8 , respectivamente. Entretanto, las muestras de ADN de los cuatro controles extraídas con el QIAamp DNA Mini Kit con las modificaciones de Basuni y colaboradores (2011) [24] tuvieron una concentración de ADN y una pureza de $14,9 \mathrm{ng} / \mu \mathrm{L}, 25 \mathrm{ng} / \mu \mathrm{L}, 10,1 \mathrm{ng} / \mu \mathrm{L}$ y $25 \mathrm{ng} / \mu \mathrm{L}$ y $1,8,2,0,1,7$ y 1,6 , respectivamente.

La comparación de resultados obtenidos con cada método no mostró diferencias significativas en cuanto a la concentración de ADN obtenida por ambos métodos, pero sí al índice de pureza del ADN extraído (véase tabla 1). También se observaron diferencias en el valor de Ct obtenido en la qPCR para una misma muestra control positivo, analizada por duplicado y extraída usando ambos métodos (véanse figuras 1 y 2). En relación con las muestras extraídas utilizando el QIAamp DNA Stool Mini Kit, cuyo Ct fue de 33, al realizar una dilución de la muestra no se evidenciaron cambios significativos en el valor de Ct en comparación con la muestra sin diluir.

\begin{tabular}{|c|c|c|c|c|}
\hline \multicolumn{5}{|c|}{$\begin{array}{l}\text { Tabla 1. Valores } \\
\text { reza del ADN de } \\
\text { A260/A280, usa } \\
\text { Kit modificado }\end{array}$} \\
\hline \multirow[t]{2}{*}{ Estadístico* } & \multicolumn{2}{|c|}{ QIAam DNA Stool Mini Kit } & \multicolumn{2}{|c|}{ QIAamp DNA Mini Kit } \\
\hline & Concentración & Índice de pureza & Concentración & Índice de pureza \\
\hline Media & 22,0 & 2,1 & 20,4 & 1,8 \\
\hline Mediana & 17,0 & 2,4 & 18,0 & 1,8 \\
\hline $\begin{array}{l}\text { Desviación } \\
\text { estándar }\end{array}$ & 24,4 & 0,6 & 9,4 & 0,1 \\
\hline Valor $p^{* *}$ & $0,551^{\mathrm{a}}$ & $0,028^{b}$ & - & - \\
\hline \multicolumn{5}{|c|}{$\begin{array}{l}\text { * U de Mann-Whitney } \\
{ }^{* *} \text { Valor } p<0,05 \\
\text { a Valor } p \text { para la comparación de la concentración de ADN obtenida por ambos métodos } \\
\text { b Valor } p \text { obtenido al comparar el índice de pureza (A260/A280) del ADN extraído con cada método }\end{array}$} \\
\hline
\end{tabular}




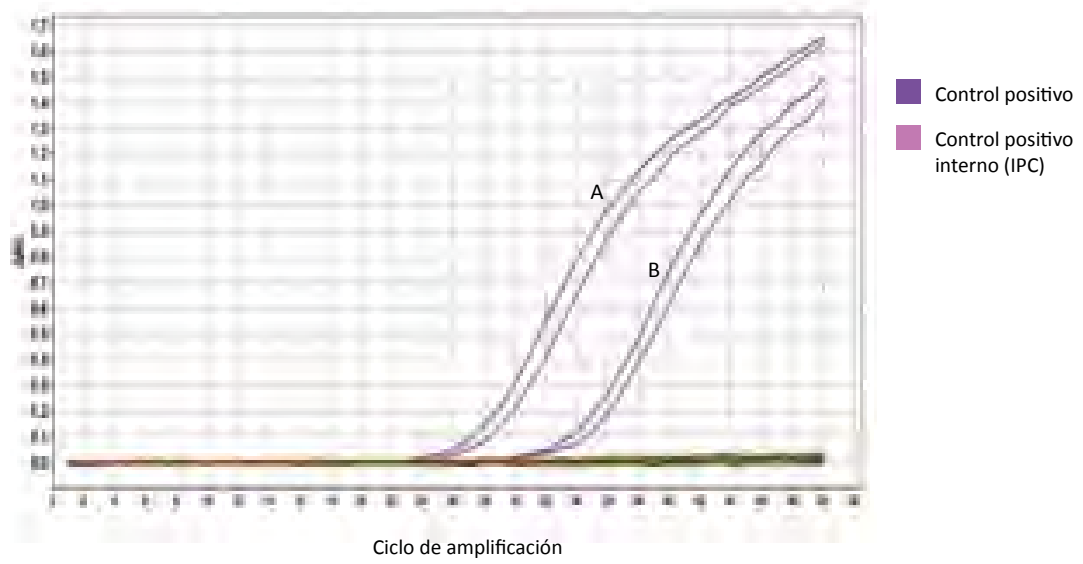

Figura 1. Curva de amplificación (Ct) de un control positivo para Strongyloides stercoralis extraído con QIAamp DNA Mini Kit y DNA Stool Mini Kit. Valores del $\triangle$ Rn para cada ciclo de amplificación. A. Curva de amplificación de un control positivo extraído con QIAamp DNA Mini Kit $(\mathrm{Ct}=28)$ y el Ct del control positivo interno $(\mathrm{Ct}=29)$. B. Curva de amplificación del mismo control positivo extraído con DNA Stool Mini Kit $(\mathrm{Ct}=35)$ y el $\mathrm{Ct}$ del control positivo interno $(\mathrm{Ct}=36) . \Delta \mathrm{Rn}$ : magnitud de la señal generada bajo las condiciones de la PCR.

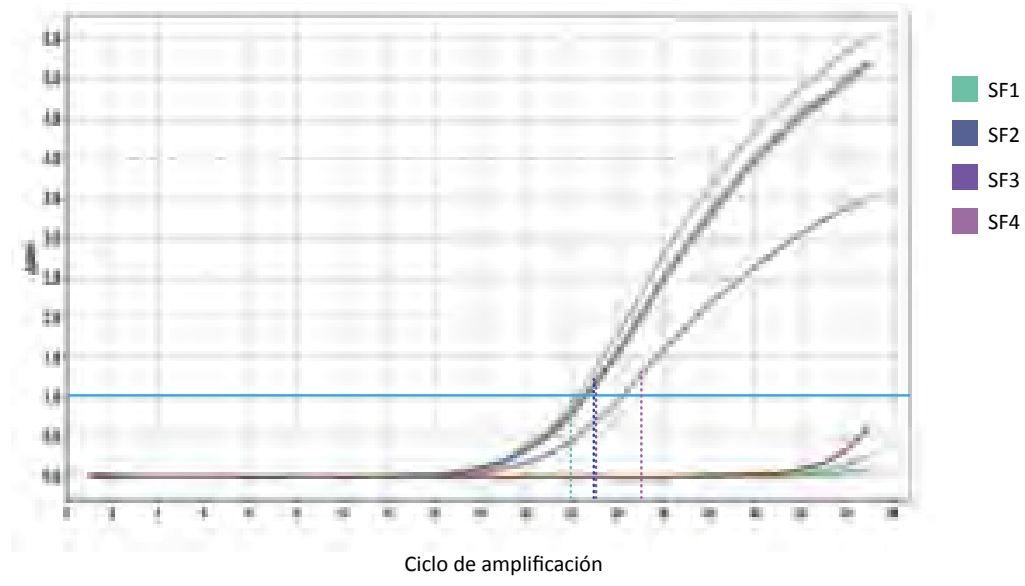

Figura 2. Valores umbral del ciclo de amplificación (Ct) de los cuatros controles positivos para Strongyloides stercoralis mediante examen directo de heces. La línea verde azul (SF1) corresponde a una muestra de una persona con hiperinfección $(\mathrm{Ct}=22$ ), las líneas azul oscuro y morado (SF3 y SF2, respectivamente) corresponden a muestras de pacientes con cargas parasitarias altas $(\mathrm{Ct}=23)$ y la línea fucsia $(\mathrm{SF} 4)$ también a la muestra de un paciente con una carga parasitaria alta $(\mathrm{Ct}=25)$.

Especificidad analítica in silico y amplificación del gen $18 \mathrm{~S}$ de la subunidad pequeña de ARN ribosomal mediante PCR convencional El análisis de especificidad de los cebadores estimado mediante BLASTn mostró $100 \%$ de identidad con secuencias parciales del gen $18 \mathrm{~S}$ de la subunidad pequeña del ARN ribosomal reportadas en el GenBank para Strongyloides stercoralis, con códigos de acceso KF926661 y KF926662, correspondientes a especímenes del parásito aislados en Camboya [44]. 
La temperatura de fusión (Tm; del inglés, melting temperature) básico de cada cebador fue de $54,2^{\circ} \mathrm{C}$ y $56,5^{\circ} \mathrm{C}$, y la temperatura de alineamiento (del inglés, annealing temperature) estuvo entre $60^{\circ} \mathrm{C}$ y $64^{\circ} \mathrm{C}$. No se evidenció formación de bucles ni dímeros de cebadores. Los resultados de la PCR electrónica mostraron el sitio exacto de hibridación de los cebadores en secuencias parciales y en la secuencia completa del gen $18 \mathrm{~S}$ de la subunidad pequeña del ARN ribosomal de Strongyloides stercoralis reportadas en la página de la NCBI. La unión del cebador hacia adelante (forward primer) se produjo en los nucleótidos en la posición 1.548-1.575 y del cebador reverso (reverse primer) en la posición 1.626-1.648 en la secuencia completa del gen $18 \mathrm{~S}$ de Strongyloides stercoralis reportada por Putland y colaboradores (1993) [45], código de acceso en el GenBank M84229.1, y en la secuencia parcial reportada por Dorris y colaboradores (2000) [46], código AF279916.2.

El análisis de las secuencias parciales del gen $18 \mathrm{~S}$ de la subunidad pequeña del ARN ribosomal obtenidas mediante PCR convencional para los controles positivos (SF1, SF2, SF3 y SF4) presentó un porcentaje de identidad entre el $97 \%$ y el $100 \%$ con las secuencias completas de este mismo marcador molecular reportadas para Strongyloides stercoralis por los Centros para el Control y la Prevención de Enfermedades (CDC; del inglés, Centers for Disease Control and Prevention) en el GenBanK con código de acceso M84229.1 [46] y para la secuencia parcial con código KF926662.1 reportada por Schar y colaboradores (2014) [44] en aislados de este nematodo en Camboya.

\section{Evaluación de la sensibilidad analítica de la qPCR}

El procedimiento de qPCR se estandarizó en un volumen de reacción final de 25 $\mu \mathrm{L}$. El perfil térmico utilizado en la qPCR fue: paso inicial de pre-PCR a $60^{\circ} \mathrm{C}$ por 1 minuto, $95^{\circ} \mathrm{C}$ durante 10 minutos, seguido de 40 ciclos de desnaturalización a $95{ }^{\circ} \mathrm{C}$ por 15 segundos, alineamiento a $60{ }^{\circ} \mathrm{C}$ por 1 minuto y pos-PCR a 60 ${ }^{\circ} \mathrm{C}$ por 1 minuto. Algunos de los análisis de la fase de estandarización fueron realizados sin la inclusión de los pasos de pre-PCR y pos-PCR en el perfil térmico utilizado en la qPCR.

El valor de Ct obtenido con la qPCR estandarizada para las cuatro muestras de los controles positivos, los cuales presentaban diferentes cargas parasitarias determinadas mediante microscopía, osciló entre 20 y 29 . El valor de Ct para SF1 fue de 23, el valor de Ct para SF2, SF3 y SF4 osciló entre 26 y 29. Con base en esta información y teniendo en cuenta las especificaciones del equipo para este tipo de protocolo (40 ciclos de reacción), en las que se sugiere que las amplificaciones con más de 35 ciclos se pueden deber a una cantidad de ADN demasiado baja o casi nula, o a contaminación de la muestra, se establecieron como muestras negativas para Strongyloides stercoralis aquellas que presentaron un Ct mayor o igual que 35,00, como indeterminadas las que presentaron 
un Ct entre 30,00 y 34,99, y como positivas las que presentaron un valor de Ct menor o igual que 29,99 .

\section{Evaluación de la especificidad analítica de la qPCR}

La concentración de ADN obtenida a partir de una larva de Strongyloides stercoralis fue de $0,9 \mathrm{ng} / \mu \mathrm{L}$, de dos larvas de $1,2 \mathrm{ng} / \mu \mathrm{L}$ y de cuatro larvas de 2,6 $\mathrm{ng} / \mu \mathrm{L}$. En el análisis de sensibilidad analítica estimado para la qPCR fue posible detectar con certeza la positividad de la muestra hasta la concentración mínima de 0,9 ng/ $\mu \mathrm{L}$ de ADN genómico, estableciéndose este dato como el límite de detección de esta prueba (véase tabla 2). Esto basado en los puntos de corte establecidos previamente para el valor del $\mathrm{Ct}$, considerando los resultados obtenidos con los controles positivos evaluados durante la estandarización de la prueba.

En el análisis de especificidad analítica de la qPCR se detectó un valor Ct mayor que 35 , que no representaban un aumento significativo en la fluorescencia emitida, en todas las muestras que fueron positivas para otros parásitos intestinales diferentes de Strongyloides stercoralis en el análisis microscópico de heces tales como: Ascaris lumbricoides, Trichuris trichiura, Uncinarias (Ancylostoma duodenale/Necator americanus), Hymenolepis nana, Entamoeba histolytica/Entamoeba dispar, Entamoeba hartmanni, Entamoeba coli, Endolimax nana, Giardia intestinalis, Chilomastix mesnili e Iodamoeba bütschlii, lo que sugiere que no existe una reacción cruzada entre la detección del ADN de Strongyloides stercoralis y la de ninguno de estos parásitos (véase tabla 3); además, en el análisis de los productos de amplificación de la qPCR en gel de agarosa en cuatro de los productos que presentaban un $\mathrm{Ct}$ igual a 37 y 38 no se observaron bandas, lo que confirma su negatividad para Strongyloides stercoralis (datos no mostrados).

\section{Determinación de la reproducibilidad de la qPCR}

En la evaluación de la curva estándar analizada mediante qPCR a partir de las diluciones seriadas en base 10 desde una concentración de ADN genómico de 24,8 $\mathrm{ng} / \mu \mathrm{L}$ hasta $2,48 \times 10^{-15} \mathrm{ng} / \mu \mathrm{L}$ se detectó una eficiencia de $-77,5$ y un coeficiente de correlación de 0,83 (coeficiente de determinación ajustado: 0,79; intervalo de confianza del 95\%: 0,242-0,767) (véase figura 3). 


\begin{tabular}{|c|c|c|c|}
\hline Código muestra & $\begin{array}{l}\text { Parásitos intestinales detectados en examen } \\
\text { directo de heces }\end{array}$ & $\begin{array}{l}\text { Ct control positivo } \\
\text { interno (IPC) }\end{array}$ & $\mathrm{Ct}$ \\
\hline Control positivo (SF1) & Strongyloides stercoralis & 33 & 24 \\
\hline Control positivo (SF3) & Strongyloides stercoralis & 33 & 29 \\
\hline Control negativo (CN) & Mix+agua ultrapura & 28 & 40 \\
\hline Control negativo (CN) & Mix+agua ultrapura & 28 & 40 \\
\hline 1 & $\begin{array}{l}\text { Ancylostoma duodenale/Necator americanus, } \\
\text { Trichuris trichiura y Ascaris lumbricoides }\end{array}$ & 28 & 38 \\
\hline 2 & Trichuris trichiura y Ascaris lumbricoides & 28 & 38 \\
\hline 3 & $\begin{array}{l}\text { Ancylostoma duodenale/Necator americanus, } \\
\text { Trichuris trichiura, Ascaris lumbricoides e Hyme- } \\
\text { nolepis nana }\end{array}$ & 28 & 37 \\
\hline 4 & Ascaris lumbricoides & 28 & 37 \\
\hline 5 & Hymenolepis nana & 28 & 40 \\
\hline 6 & $\begin{array}{l}\text { Hymenolepis nana, Trichuris trichiura, Ascaris } \\
\text { lumbricoides y Giardia intestinalis }\end{array}$ & 28 & 40 \\
\hline 7 & $\begin{array}{l}\text { Hymenolepis nana, Ascaris lumbricoides y Tri- } \\
\text { churis trichiura }\end{array}$ & 28 & 40 \\
\hline 8 & Trichuris trichiura & 28 & 37 \\
\hline 9 & $\begin{array}{l}\text { Hymenolepis nana, Trichuris trichiura y Ancylos- } \\
\text { toma duodenale/Necator americanus }\end{array}$ & 28 & 40 \\
\hline 10 & Hymenolepis nana y Trichuris trichiura & 28 & 38 \\
\hline 11 & $\begin{array}{l}\text { Entamoeba histolytica/Entamoeba dispar, Enta- } \\
\text { moeba hartmanni, Entamoeba coli y Chilomastix } \\
\text { mesnili }\end{array}$ & 28 & 40 \\
\hline 12 & $\begin{array}{l}\text { Entamoeba histolytica/Entamoeba dispar, Enta- } \\
\text { moeba hartmanni y Entamoeba coli }\end{array}$ & 28 & 38 \\
\hline 13 & $\begin{array}{l}\text { Iodamoeba bütschlii, Endolimax nana, Ascaris } \\
\text { lumbricoides, Trichuris trichiura y Ancylostoma } \\
\text { duodenale/Necator americanus }\end{array}$ & 28 & 39 \\
\hline 14 & $\begin{array}{l}\text { Ascaris lumbricoides, Trichuris trichiura, Enta- } \\
\text { moeba histolytica/Entamoeba dispar, Iodamoeba } \\
\text { bütschlii e Hymenolepis nana }\end{array}$ & 28 & 40 \\
\hline 15 & $\begin{array}{l}\text { Ascaris lumbricoides, Giardia intestinalis, Enta- } \\
\text { moeba coli y Chilomastix mesnili }\end{array}$ & 28 & 37 \\
\hline 16 & $\begin{array}{l}\text { Ascaris lumbricoides, Hymenolepis nana, Enta- } \\
\text { moeba histolytica/Entamoeba dispar, Iodamoeba } \\
\text { bütschlii y Giardia intestinalis }\end{array}$ & 28 & 38 \\
\hline \multicolumn{4}{|c|}{ Ct: valores umbral del ciclo de amplificación } \\
\hline
\end{tabular}




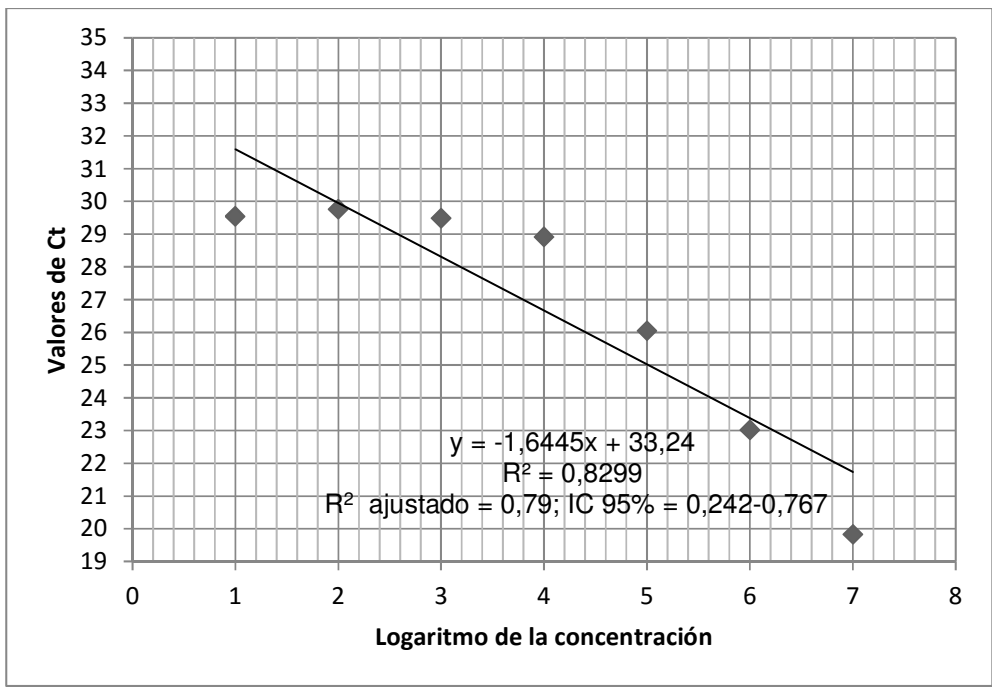

Figura 3. Curva estándar para determinar la eficiencia de la qPCR.

En cuanto a la reproducibilidad de la qPCR estandarizada utilizando estas mismas concentraciones de ADN se observaron valores de Ct similares tanto al analizar simultáneamente tres reacciones de PCR (reproducibilidad intraensayo) como en tres días diferentes (reproducibilidad interensayo). Independientemente del día y del ensayo el valor de Ct osciló siempre entre 20,0 y 29,8 para todas las concentraciones probadas (véase figura 4). Esta comparación arrojó un coeficiente de correlación intraclase de 0,882 (intervalo de confianza del 95\%: 0,478-0,973).

\section{Discusión}

En el presente estudio se estandarizó una qPCR para el diagnóstico de Strongyloides stercoralis al amplificar un fragmento de $101 \mathrm{pb}$ del gen del $18 \mathrm{~S}$ del ARN ribosomal. Cabe destacar que para la estandarización de métodos basados en la detección de ADN es necesaria la implementación de técnicas de extracción muy eficientes que permitan mejorar la pureza del ADN extraído y, por ende, el rendimiento [47].

Los resultados obtenidos en la evaluación de los protocolos de extracción indican que el ADN extraído a partir de materia fecal empleando el estuche comercial QIAamp DNA Mini Kit de QIAGEN ${ }^{\circledR}$ con las modificaciones hechas por Basuni y colaboradores (2011) [24] arrojó una menor concentración de ADN, pero mostró una mejor pureza que el extraído con los otros protocolos empleados; además, el tiempo de procesamiento de la muestra posterior a la incubación es menor en este protocolo. Debido a que la pureza del ADN puede afectar en mayor grado el desempeño de la PCR es preciso que el método de extracción empleado proporcione un ADN no degradado, sin proteínas e inhibidores, que permita resultados y patrones reproducibles [48]. 
A

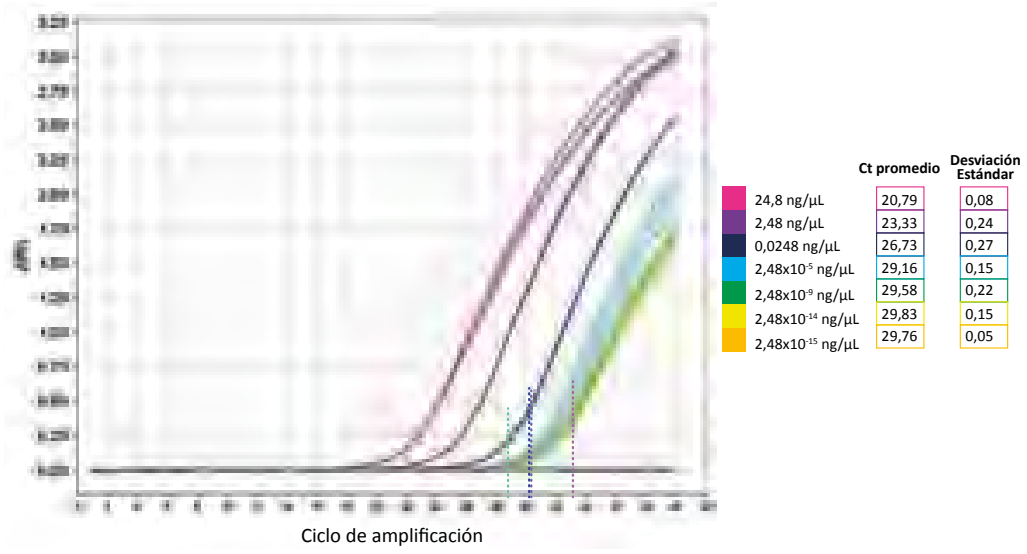

B

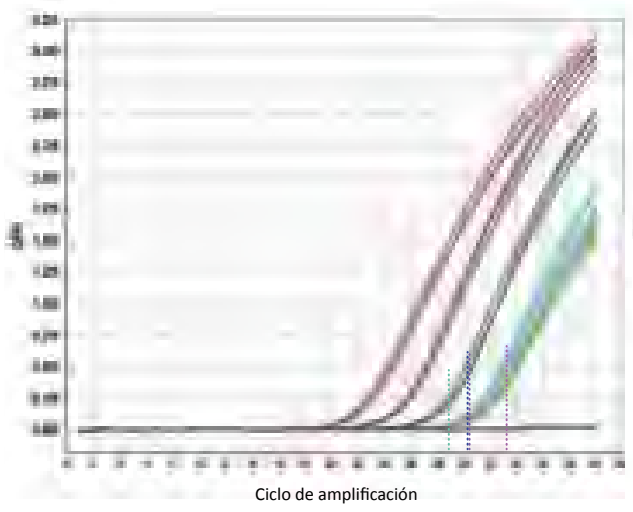

C

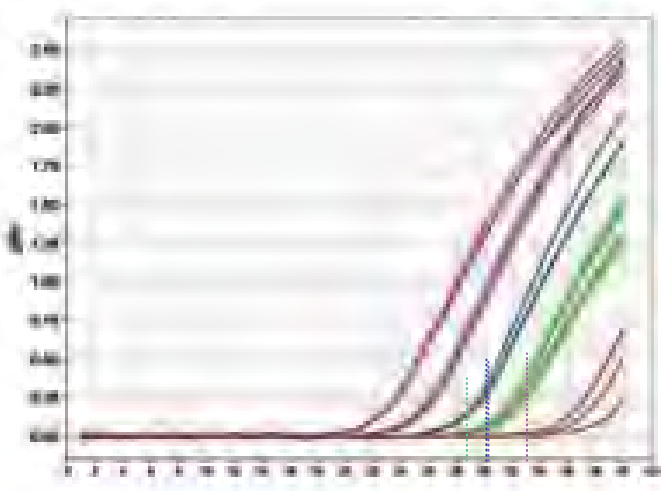

Ciclo de amplificación

Figura 4. Curvas de amplificación de diluciones de los controles positivos, concentración inicial: 24,8 ng/ $\mu \mathrm{L}$ y concentración final 2,48×10-15 ng/ $\mu \mathrm{L}$. Ct: valores del ciclo umbral de amplificación. En A, B y C se muestran las curvas de amplificación correspondientes a reacciones corridas en tres días diferentes. Cada color representa una concentración de la muestra. También se incluyen los valores de Ct promedio y la desviación estándar de cada uno.

Al comparar la amplificación mediante qPCR del ADN extraído con los protocolos QIAamp DNA Stool Mini Kit de QIAGEN ${ }^{\circledR}$ y QIAamp DNA Mini Kit de QIAGEN ${ }^{\circledR}$ con las modificaciones propuestas por Basuni y colaboradores (2011) [24] se encontró que las muestras extraídas con el segundo método exhibieron un $\mathrm{Ct}$ menor, lo que indica que, aunque el protocolo de QIAamp DNA Stool Mini Kit es específico para la extracción de ácidos nucleicos a partir de muestras de materia fecal y arrojó una mayor concentración de ADN de Strongyloides stercoralis, la presencia de proteínas en las muestras extraídas con este estuche puede generar deficiencia en la amplificación [49].

Los hallazgos en la evaluación de los cebadores demostraron que son específicos para la detección de Strongyloides stercoralis, con un porcentaje de identidad del $100 \%$ al utilizar las secuencias parciales del parásito reportadas en la NCBI. 
Sumado a esto, en el análisis realizado en el programa Oligoanalyzer y en la PCR electrónica, los parámetros como el contenido de guanina-citosina (G-C), la temperatura de fusión (Tm) y la temperatura de alineamiento fueron similares. El hecho de que los cebadores arrojen un alto porcentaje de identidad con las secuencias de Strongyloides stercoralis favorece la especificidad de la qPCR; además, la longitud de estos ( 28 pb y 23 pb) disminuye la posibilidad de formación de estructuras que interfieran con el alineamiento [50].

Otro aspecto a resaltar en el presente estudio es el valor del ciclo umbral o Ct obtenido para los diferentes controles. La muestra de materia fecal procedente de un paciente con hiperinfección arrojó un valor de 23, mientras que para los demás controles positivos procedentes de pacientes con cargas parasitarias altas el valor de Ct estuvo en aumento. En concordancia, Schar y colaboradores (2013) [26] observaron un aumento en el valor del Ct obtenido de muestras de materia fecal de personas asintomáticas, las cuales presentaban cargas parasitarias bajas observadas mediante examen microscópico; no obstante, para establecer la relación existente entre la carga parasitaria y la eficiencia de la amplificación mediante qPCR se requiere de futuros estudios que evalúen la correlación entre el valor de Ct obtenido y la intensidad de la infección por Strongyloides stercoralis. Es de resaltar que en algunos instructivos de equipos de PCR en tiempo real se especifica que los valores de $\mathrm{Ct}$ mayores o iguales a 35 pueden indicar una baja cantidad de ADN molde en la muestra o contaminación ambiental de esta [51], por lo que es necesario recurrir a la evaluación de los productos de amplificación mediante un gel de agarosa para verificar el tamaño del amplicón obtenido [52].

En cuanto a los ensayos de reproducibilidad se observó la falta de linealidad en los datos obtenidos en la curva estándar de la qPCR cuando las concentraciones de ADN disminuyen en la muestra, lo que señala que a menor cantidad de ADN analizada el rendimiento de la PCR disminuye [47]. Para esto, se podría implementar un método de concentración previo a la extracción para garantizar cantidades suficientes de ADN en las muestras a analizar, ya que se observa una buena reproducibilidad y linealidad del método a altas concentraciones de este.

Estudios previos, en los cuales se han valorado varios protocolos de extracción de ADN a partir de muestras de materia fecal en función del rendimiento y la eficiencia de la PCR [53-55], han sugerido que el tratamiento de las muestras con métodos físicos como la sonicación o la incubación a temperaturas entre $50{ }^{\circ} \mathrm{C}$ y $100{ }^{\circ} \mathrm{C}$, con el uso de enzimas como la proteinasa $\mathrm{K}$, mejoran la eficiencia y rendimiento de la técnica. Aunque en el presente estudio se emplearon algunos de los tratamientos sugeridos en dichas investigaciones es necesario enfocar esfuerzos técnicos adicionales para optimizar aún más los procedimientos de extracción de ADN genómico a partir de muestras de materia fecal que mejoren el desempeño y la eficiencia de la qPCR evaluada. 
La sensibilidad analítica de la qPCR evaluada en este trabajo para la detección de Strongyloides stercoralis al emplear cuatro controles positivos (detectados por microscopía) fue del $100 \%$, similar a lo reportado por Sultana y colaboradores (2013) [33], donde la qPCR estandarizada detectó el 100\% de las muestras analizadas que tenían cargas parasitarias altas. Esto sugiere la importancia de la concentración de ADN en la muestra para obtener resultados positivos confiables mediante qPCR.

Es importante resaltar que el análisis de las secuencias de los cuatro productos de amplificación obtenidos presentó un porcentaje de identidad entre el $98 \%$ y el $100 \%$ con Strongyloides stercoralis, y que la especificidad, la sensibilidad y la reproducibilidad de los cebadores utilizados para la detección de Strongyloides stercoralis se ha comprobado y ha sido reportada por diferentes autores para la implementación de diferentes tipos de PCR como PCR convencional, PCR multiplex y qPCR [34].

\section{Conclusiones}

En este estudio la qPCR evaluada para la detección de Strongyloides stercoralis presentó altos valores de sensibilidad y especificidad, con una buena correlación de las cargas parasitarias altas detectadas con la positividad por microscopía de muestras de materia fecal. Sin embargo, con el alcance del presente trabajo aún no es posible interpretar la utilidad clínica de esta técnica para este fin. A futuro, en nuestro grupo de investigación, el proceso de validación de esta qPCR se realizará en tres grupos de participantes con diferentes condiciones epidemiológicas para adquirir la estrongiloidiasis: un grupo de una zona geográfica con condiciones favorables para adquirir infecciones parasitarias por geohelmintos, otro con condiciones menos favorables para adquirir la infección y un último conformado por personas con inmunosupresión controlada mediante el uso de corticosteroides.

\section{Agradecimientos}

El presente trabajo es un producto derivado del desarrollo de la propuesta de investigación código de radicado interno 252B-08/14-44 aprobada por el Centro de Investigación para el Desarrollo y la Innovación-CIDI de la Universidad Pontificia Bolivariana, Medellín, Colombia.

\section{Bibliografía}

1. Brenneck J, Mattia A. Images in clinical medicine. Strongyloides stercoralis infestation. N Engl J Med 1996; 334: 1173.

2. Ali SM, Dormer AE. Hyperinfection syndrome with Strongyloides stercoralis. Postgrad Med J 1981; 57: 126-128.

3. Simpson WG, Gerhardstein DC, Thompson JR. Disseminated Strongyloides stercoralis infec- tion. South Med J 1993; 86: 821-825.

4. Cappello $\mathbf{M}$, Hotez PJ. Disseminated strongyloidiasis. Semin Neurol 1993; 13: 169-174.

5. Olsen A, van Lieshout L, Marti $H$, Polderman $\mathbf{T}$, Polman $\mathbf{K}$, Steinmann $\mathbf{P}$, et al. Strongyloidiasis--the most neglected of the neglected tropical diseases? Trans R Soc Trop Med Hyg 2009; 103 : 967-972. 
6. Bisoffi Z, Buonfrate D, Montresor A, Requena-Mendez A, Munoz J, Krolewiecki AJ, et al. Strongyloides stercoralis: a plea for action. PLoS Negl Trop Dis 2013; 7: e2214.

7. Schar F, Trostdorf U, Giardina F, Khieu $\mathbf{V}_{\boldsymbol{r}}$ Muth S, Marti H, et al. Strongyloides stercoralis: Global Distribution and Risk Factors. PLoS Negl Trop Dis 2013; 7: e2288.

8. Montes M, Sawhney C, Barros N. Strongyloides stercoralis: there but not seen. Curr Opin Infect Dis 2010; 23: 500-504.

9. Agrawal V, Agarwal T, Ghoshal UC. Intestinal strongyloidiasis: a diagnosis frequently missed in the tropics. Trans R Soc Trop Med Hyg 2009; 103: 242-246.

10. Botero D, Restrepo M. Parasitosis Humana: Incluye animales venenosos y ponzoñosos (ed $5 a$ ). Medellín, Colombia: Corporación para Investigaciones Biológicas; 2012.

11. Anamnart W, Pattanawongsa A, Intapan PM, Maleewong $\mathbf{W}$. Factors affecting recovery of Strongyloides stercoralis larvae: an approach to a newly modified formalin-ether concentration technique for diagnosis of strongyloidiasis. J Clin Microbiol 2010; 48: 97-100.

12. Campo Polanco L, Gutiérrez LA, Cardona Arias J. Infección por Strongyloides stercoralis: metanálisis sobre evaluación de métodos diagnósticos convencionales (1980-2013). Rev Esp Salud Publica 2014; 88: 581-600.

13. Siddiqui AA, Berk SL. Diagnosis of Strongyloides stercoralis infection. Clin Infect Dis 2001; 33: 1040-1047.

14. Nielsen PB, Mojon M. Improved diagnosis of strongyloides stercoralis by seven consecutive stool specimens. Zentralbl Bakteriol Mikrobiol Hyg A 1987; 263: 616-618.

15. Marchi Blatt J, Cantos GA. Evaluation of techniques for the diagnosis of Strongyloides stercoralis in human immunodeficiency virus (HIV) positive and HIV negative individuals in the city of Itajai, Brazil. Braz J Infect Dis 2003; 7: 402-408.

16. Intapan PM, Maleewong $\mathbf{W}$, Wongsaroj $\mathbf{T}$, Singthong S, Morakote $\mathbf{N}$. Comparison of the quantitative formalin ethyl acetate concentration technique and agar plate culture for diagnosis of human strongyloidiasis. J Clin Microbiol 2005; 43: 1932-1933.

17. Hernandez-Chavarria F, Avendano L. A simple modification of the Baermann method for diagnosis of strongyloidiasis. Mem Inst Oswaldo Cruz 2001; 96: 805-807.

18. Abdul-Fattah MM, Nasr ME, Yousef SM, Ibraheem MI, Abdul-Wahhab SE, Soliman HM. Efficacy of ELISA in diagnosis of strongyloidiasis among the immune-compromised patients. J Egypt Soc Parasitol 1995; 25: 491-498.

19. Conway DJ, Atkins NS, Lillywhite JE, Bailey JW, Robinson RD, Lindo JF, et al. Immunodiagnosis of Strongyloides stercoralis infection: a method for increasing the specificity of the indirect ELISA. Trans R Soc Trop Med Hyg 1993; 87: 173-176.

20. Boscolo M, Gobbo M, Mantovani W, Degani
M, Anselmi M, Monteiro GB, et al. Evaluation of an indirect immunofluorescence assay for strongyloidiasis as a tool for diagnosis and follow-up. Clin Vaccine Immunol 2007; 14: 129-133.

21. Koosha S, Fesharaki M, Rokni MB. Comparison of enzyme-linked immunosorbent assay and indirect immunofluorescence assay in the diagnosis of human strongyloidiasis. Indian J Gastroenterol 2004; 23: 214-216.

22. Huaman MC, Sato $Y$, Aguilar JL, Terashima A, Guerra H, Gotuzzo E, et al. Gelatin particle indirect agglutination and enzyme-linked immunosorbent assay for diagnosis of strongyloidiasis using Strongyloides venezuelensis antigen. Trans R Soc Trop Med Hyg 2003; 97: 535-538.

23. Sithithaworn J, Sithithaworn $\mathbf{P}$, Janrungsopa T, Suvatanadecha K, Ando K, Haswell-EIkins MR. Comparative assessment of the gelatin particle agglutination test and an enzyme-linked immunosorbent assay for diagnosis of strongyloidiasis. J Clin Microbiol 2005; 43: 3278-3282.

24. Basuni M, Muhi J, Othman N, Verweij JJ, Ah$\operatorname{mad} \mathbf{M}$, Miswan $\mathbf{N}$, et al. A pentaplex real-time polymerase chain reaction assay for detection of four species of soil-transmitted helminths. Am J Trop Med Hyg 2011; 84: 338-343.

25. Moghaddassani $\mathbf{H}$, Mirhendi $\mathbf{H}$, Hosseini $\mathbf{M}$, Rokni M, Mowlavi G, Kia E. Molecular Diagnosis of Strongyloides stercoralis Infection by PCR Detection of Specific DNA in Human Stool Samples. Iran J Parasitol 2011; 6: 23-30.

26. Schar F, Odermatt $\mathbf{P}$, Khieu V, Panning $\mathbf{M}$, Duong S, Muth $\mathbf{S}$, et al. Evaluation of real-time PCR for Strongyloides stercoralis and hookworm as diagnostic tool in asymptomatic schoolchildren in Cambodia. Acta Trop 2013; 126: 89-92.

27. Anderson NW, Klein DM, Dornink SM, Jespersen DJ, Kubofcik J, Nutman TB, et al. Comparison of three immunoassays for detection of antibodies to Strongyloides stercoralis. Clin Vaccine Immunol 2014; 21: 732-736.

28. Buonfrate D, Sequi M, Mejia R, Cimino Ro, Krolewiecki AJ, Albonico M, et al. Accuracy of five serologic tests for the follow up of Strongyloides stercoralis infection. PLoS Negl Trop Dis 2015; 9: e0003491.

29. Gomes Tdos S, Garcia MC, de Souza Cunha F, Werneck de Macedo H, Peralta JM, Peralta RH. Differential diagnosis of Entamoeba spp. in clinical stool samples using SYBR green real-time polymerase chain reaction. ScientificWorldJournal 2014; 2014: 645084.

30. Van Lint $\mathbf{P}$, Rossen JW, Vermeiren S, Ver Elst K, Weekx S, Van Schaeren J, et al. Detection of Giardia lamblia, Cryptosporidium spp. and Entamoeba histolytica in clinical stool samples by using multiplex real-time PCR after automated DNA isolation. Acta Clin Belg 2013; 68: 188-192.

31. Lalonde LF, Gajadhar AA. Highly sensitive and specific PCR assay for reliable detection of Cyclospora cayetanensis oocysts. Appl Environ Microbiol 2008; 74: 4354-4358.

32. Stark D, Al-Qassab SE, Barratt JL, Stanley K, Roberts T, Marriott D, et al. Evaluation of multiplex tandem real-time PCR for detection of 
Cryptosporidium spp., Dientamoeba fragilis, Entamoeba histolytica, and Giardia intestinalis in clinical stool samples. J Clin Microbiol 2011; 49: 257-262.

33. Sultana $\mathbf{Y}$, Jeoffreys $\mathbf{N}$, Watts MR, Gilbert GL, Lee $\mathbf{R}$. Real-time polymerase chain reaction for detection of Strongyloides stercoralis in stool. Am J Trop Med Hyg 2013; 88: 1048-1051.

34. Verweij JJ, Canales M, Polman K, Ziem J, Brienen EA, Polderman AM, et al. Molecular diagnosis of Strongyloides stercoralis in faecal samples using real-time PCR. Trans R Soc Trop Med Hyg 2009; 103: 342-346.

35. Sitta RB, Malta FM, Pinho JR, Chieffi PP, Gryschek RC, Paula FM. Conventional PCR for molecular diagnosis of human strongyloidiasis. Parasitology 2014; 141: 716-721.

36. Janwan $\mathbf{P}$, Intapan PM, Thanchomnang $\mathbf{T}$, Lulitanond V, Anamnart W, Maleewong $W$ Rapid detection of Opisthorchis viverrini and Strongyloides stercoralis in human fecal samples using a duplex real-time PCR and melting curve analysis. Parasitol Res 2011; 109: 1593-1601.

37. Ramachandran S, Gam AA, Neva FA. Molecular differences between several species of Strongyloides and comparison of selected isolates of S. stercoralis using a polymerase chain reaction-linked restriction fragment length polymorphism approach. Am J Trop Med Hyg 1997; 56 : 61-65.

38. Sato H, Suzuki K, Osanai A, Kamiya H, Furuoka $\mathbf{H}$. Identification and characterization of the threadworm, Strongyloides procyonis, from feral raccoons (Procyon lotor) in Japan. J Parasitol 2006; 92: 63-68.

39. Paula FM, Malta Fde M, Marques PD, Sitta RB Pinho JR, Gryschek RC, et al. Molecular diagnosis of strongyloidiasis in tropical areas: a comparison of conventional and real-time polymerase chain reaction with parasitological methods. Mem Inst Oswaldo Cruz 2015; 110: 272-274.

40. Pakdee W, Thaenkham U, Dekumyoy $\mathbf{P}$, Sa-Nguankiat S, Maipanich W, Pubampen S. Genetic differentiation of strongyloides stercoralis from two different climate zones revealed by $18 \mathrm{~S}$ ribosomal DNA sequence comparison. Southeast Asian J Trop Med Public Health 2012; 43: 13331338.

41. Hasegawa $\mathbf{H}$, Sato $\mathbf{H}$, Fujita S, Nguema PP, Nobusue K, Miyagi K, et al. Molecular identification of the causative agent of human strongyloidiasis acquired in Tanzania: dispersal and diversity of Strongyloides spp. and their hosts. Parasitol Int 2010; 59: 407-413.

42. Labes EM, Nurcahyo W, Deplazes P, Mathis A. Genetic characterization of Strongyloides spp. from captive, semi-captive and wild Bornean orangutans (Pongo pygmaeus) in Central and East Kalimantan, Borneo, Indonesia. Parasitology 2011; 138: 1417-1422.
43. Kramme S, Nissen N, Soblik H, Erttmann $K_{\text {, }}$ Tannich E, Fleischer B, et al. Novel real-time PCR for the universal detection of Strongyloides species. J Med Microbiol 2011; 60: 454-458.

44. Schar F, Guo L, Streit A, Khieu V, Muth S, Marti $\mathbf{H}$, et al. Strongyloides stercoralis genotypes in humans in Cambodia. Parasitol Int 2014; 63: 533-536.

45. Putland RA, Thomas SM, Grove DI, Johnson AM. Analysis of the $18 \mathrm{~S}$ ribosomal RNA gene of Strongyloides stercoralis. Int J Parasitol 1993; 23: 149-151.

46. Dorris $\mathbf{M}$, Blaxter $\mathbf{M}$. The small subunit ribosomal RNA sequence of Strongyloides stercoralis. Int Parasitol 2000; 30: 939-941.

47. Fraga-Nodarse J, Rodríguez J, Fuentes $\mathbf{0}$ Castex M, Fernández-Calienes A. Comparación entre 5 métodos para la extracción de ADN de Triatomíneos: su utilización en la técnica de ADN polimórfico amplificado al azar (RAPD). Rev Cubana Med Trop 2004; 56: 203-207.

48. Leite DC, Balieiro FC, Pires CA, Madari BE, Rosado AS, Coutinho HL, et al. Comparison of DNA extraction protocols for microbial communities from soil treated with biochar. Braz J Microbiol 2014; 45: 175-183.

49. Schrader C, Schielke A, Ellerbroek L, Johne R. PCR inhibitors - occurrence, properties and removal. J Appl Microbiol 2012; 113: 1014-1026.

50. Poritz MA, Ririe KM. Getting Things Backwards to Prevent Primer Dimers. The Journal of Molecular Diagnostics; 16: 159-162.

51. Applied Biosystems. Applied Biosystems 7500/7500 Fast Real-Time PCR System Standard Curve Experiments. California, Estados Unidos. 2010. Disponible: https://www3.appliedbiosystems.com/cms/groups/mcb_support/documents/ generaldocuments/cms 050329.pdf. Consultado: oct 2016.

52. Garibyan L, Avashia N. Research Techniques Made Simple: Polymerase Chain Reaction (PCR). J Invest Dermatol 2013; 133: e6.

53. Demeler J, Ramunke S, Wolken S, Ianiello D, Rinaldi L, Gahutu JB, et al. Discrimination of gastrointestinal nematode eggs from crude fecal egg preparations by inhibitor-resistant conventional and real-time PCR. PLoS One 2013; 8: e61285.

54. Adamska M, Leonska-Duniec A, Maciejewska A, Sawczuk M, Skotarczak B. Comparison of efficiency of various DNA extraction methods from cysts of Giardia intestinalis measured by PCR and TaqMan real time PCR. Parasite 2010; 17: 299305

55. Nunes CM, Lima LG, Manoel CS, Pereira RN, Nakano MM, Garcia JF. Fecal specimens preparation methods for PCR diagnosis of human taeniosis. Rev Inst Med Trop Sao Paulo 2006; 48: 4547. 